\title{
Cambios en la industria y en el paisaje vitivinícola de la Denominación de Origen de Cigales (Castilla y León, España)
}

\section{Changes in the industry and landscape wine of the guarantee of origin of Cigales (Castile and León, Spain)}

\author{
Julio Fernández Portela*
}

La industria vitivinícola en Castilla y León ha experimentado importantes transformaciones a lo largo de su historia. Desde la producción de vinos para el autoabastecimiento hasta la elaboración de caldos de calidad han pasado muchos siglos y se han acometido cambios muy relevantes en las estructuras productivas de las diferentes bodegas presentes en la región. Sin duda alguna la evolución sufrida por este sector ha sobrepasado la propia actividad vitivinícola y ha conseguido cambiar de forma sustancial las comarcas tradicionales productoras de vino, convirtiendo a alguna de ellas — como la Ribera del Duero o Rueda - en unas de las Denominaciones de Origen más prósperas de España (Clarke, 2005), además de modernizar sus estructuras socioeconómicas y diversificar el tejido económico y empresarial con nuevas actividades relacionadas con el mundo del vino que han ayudado a incrementar las rentas agrarias y, en algunas ocasiones, a fijar nueva población o mantener la existente entre otros aspectos.

A partir de 1980, con el nombramiento de las primeras Denominaciones de Origen (D.O.) en Castilla y León, pero sobre todo a partir de la década de 1990, se produjo un reconocimiento de esta rama de la industria agroalimen-

* Investigador del Programa de Formación de Profesorado Universitario (FPU) del Ministerio de Educación. Departamento de Geografía, Universidad de Valladolid (juliofernandez potela@ hotmail.com). 
taria convirtiéndola en uno de los emblemas de la región y en un buen embajador en el extranjero (Alonso Santos et al., 2003a).

El nombramiento de las diversas D.O. desencadenó un proceso de modernización e innovación importante en la industria vitivinícola de la región, especialmente en algunas D.O. como Rueda, Ribera del Duero, Toro o El Bierzo, a través de una serie de agentes implicados en este proceso - los bodegueros, los viticultores o las administraciones públicas-, que ha tenido consecuencias positivas en este sector por la atracción de capital exógeno, la expansión de los mercados, la promoción del producto en diversos eventos y plataformas digitales, la incorporación del personal cualificado para desempeñar las diferentes tareas en el campo y en la bodega, la formación de nuevos viticultores o la diversificación económica de esta actividad principalmente hacia el ámbito del enoturismo (Alonso Santos et al., 2003b; Sánchez Hernández, 2003a; Sánchez Hernández, 2003b; Alonso Santos et al., 2005; Aparicio et al., 2008).

Cigales ha seguido la estela de estas cuatro D.O. mencionadas en lo respectivo al proceso de innovación y de modernización de la industria. Aunque la orientación vitivinícola de esta comarca se aleja en el tiempo fue la aparición del Consejo Regulador en 1991 el motor principal de los cambios acometidos durante los poco más de veinte años de vida que posee. El nombramiento de la D.O., así como la adhesión a otros sellos de certificación, han ayudado - y lo siguen haciendo- a promocionar los productos agroalimentarios autóctonos y artesanales de forma fiable y segura, fomentando este tipo de industria y revalorizando el potencial endógeno que poseen los municipios en los que se asientan (Tolón y Lastra, 2009). Esto ha permitido la modernización del sector vitivinícola con la renovación de las bodegas por la introducción de los sistemas más actuales en las técnicas de vinificación y de conservación del vino, se ha incorporado personal cualificado de diversas ramas del sector y se ha conseguido crear un tejido económico más sólido complementario a esta industria. Aunque Cigales se encuentra distante respecto a la situación existente en la Ribera del Duero o Rueda sigue la senda que antes han recorrido estas D.O. y poco a poco está consiguiendo abrirse un hueco en el panorama vitivinícola nacional.

\section{OBjeTIVOS, METODOLOGÍA Y ESTRUCTURA}

El artículo pretende analizar las transformaciones ocurridas en la industria vitivinícola y en el paisaje de la D.O. Cigales a través de la evolución en la superficie cultivada, en los nuevos métodos de plantación, la construcción de nuevas bodegas industriales, el origen de su capital o las nuevas actividades 
que desempeñan y que constituyen una nueva orientación a la actividad clásica de la producción de vino.

Este espacio vitivinícola se sitúa en el centro de Castilla y León, en el corredor de la A-62 que comunica Valladolid y Palencia por el territorio conocido como bajo valle del Pisuerga entre los páramos del Cerrato y de Torozos. Está compuesto por un total de doce municipios, once pertenecen a la provincia de Valladolid como son los de Cabezón de Pisuerga, Cigales, Corcos del Valle, Cubillas de Santa Marta, Fuensaldaña, Mucientes, Quintanilla de Trigueros, San Martín de Valvení, Santovenia de Pisuerga, Trigueros del Valle y Valoria la Buena, además de Dueñas, que pertenece a Palencia. A estos municipios hay que añadir el pago denominado El Berrocal —integrado en el municipio de Valladolid-, por lo que en su conjunto poseen $574 \mathrm{~km}^{2}$ (figura 1).

\section{FIGURA 1}

\section{LOCALIZACIÓN DE LA D.O. CIGALES}

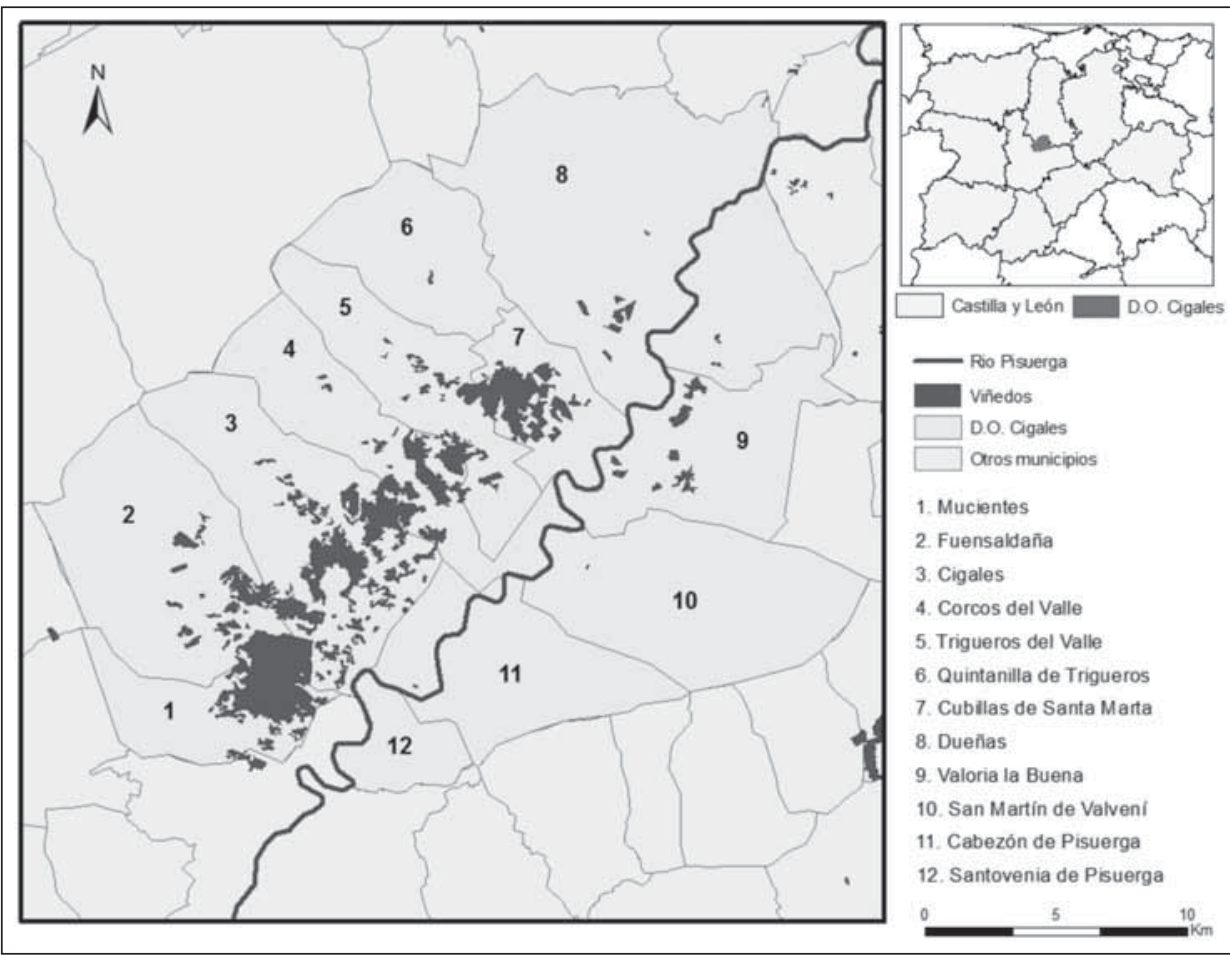

Fuente: elaboración propia. 
El periodo de estudio elegido para este análisis se centra en algo más de veinte años (1987-2008). Las fechas escogidas se deben a diversos factores. Como comienzo del estudio se ha elegido 1987 que permite ver la importancia que tenía esta actividad antes de su constitución como D.O. y 2008 por ser los últimos datos disponibles que se poseen a esta escala. Entre medias de este periodo se han elegido otros dos años: 1994 con el objetivo de ver las repercusiones que tuvo el nombramiento sobre la actividad y 2001 para observar el comienzo de la expansión que se produjo gracias a la modernización del sector y de las nuevas inversiones acometidas por capital endógeno y exógeno.

Para poder analizar estos cambios se van a tener en cuenta diferentes variables que abarcan la evolución de la superficie de viñedo cultivada, su peso relativo respecto al resto de cultivos o la aparición de nuevas bodegas entre otros aspectos. Para ello se han utilizado diversas fuentes y herramientas. La principal ha sido los Documentos 1T de la Junta de Castilla y León de los años 1987, 1994, 2001 y 2008. Estos documentos ofrecen la superficie total de viñedo a escala municipal de toda la región. Los datos que poseen hacen referencia a la superficie total de viñedo inscrita o no a una D.O. o a cualquier otra figura de calidad, y que gracias a los Sistemas de Información Geográfica (SIG) se han podido plasmar en una serie de cartogramas que permiten ver su distribución espacio-temporal en la comarca.

Para el estudio se ha decidido utilizar estos datos ya que el paisaje vitivinícola de la comarca lo forman todas las hectáreas de viñedo - formen parte o no de la D.O.- por lo que de esta forma obtendremos la superficie total existente en todos los municipios además de la información facilitada por el Consejo Regulador de Cigales.

Esta información, principalmente de carácter cuantitativa, se complementa con el trabajo de campo que se ha basado en la visita de algunas bodegas y entrevistas a sus responsables, en concreto 17 de las 33 bodegas existentes (51,5\% del total). La muestra de las bodegas elegidas se ha realizado teniendo en cuenta algunas de sus características como la capacidad de la bodega, la superficie que controlan de viñedo, el origen de su capital o el año de su fundación, lo que ha permitido abarcar a un grupo muy representativo - desde pequeñas bodegas hasta grandes grupos empresariales- para la realización del trabajo. Para estas entrevistas se ha elaborado un cuestionario con diferentes preguntas que se han considerado fundamentales para esta investigación como el empleo que generan o el desarrollo de actividades alternativas a la producción de vino.

También se han mantenido conversaciones con viticultores de algunos de los municipios, en concreto de Cubillas de Santa Marta, Dueñas y Trigueros del Valle, que han ofrecido la versión más clásica del cultivo de la vid, la ela- 
boración del vino, así como de las funciones que se desempeñaban en las tradicionales bodegas subterráneas (Fernández Portela, 2011).

El trabajo de campo realizado en los doce municipios que conforman esta D.O. ha permitido elaborar, entre otras cosas, un listado con las bodegas existentes en cada uno de ellos además de observar sus diferentes tipologías constructivas desde las subterráneas a los grandes complejos vitivinícolas realizados a modelo de los Chateau franceses ${ }^{1}$ que se sitúan a lo largo de las vías de comunicación.

De esta forma el artículo se estructura en cinco epígrafes en los que se pretende destacar los aspectos más característicos de este espacio vitivinícola como pueden ser sus condicionantes ecológicos, su tradición histórica, la orientación hacia la producción de vinos de calidad, la construcción de nuevas bodegas y la expansión del enoturismo. Finalmente el artículo termina con una serie de conclusiones que pretenden destacar las transformaciones económicas y paisajísticas más relevantes ocurridas en estos municipios.

Para poder desarrollar esta investigación es necesario conocer los orígenes de este producto, que se remontan varios siglos atrás, así como los condicionantes ecológicos que permiten que en este espacio de la región se produzcan vinos de buena calidad.

LA HISTORIA DE LA VID Y EL VINO CONDICIONADA POR LAS CARACTERÍSTICAS ECOLÓGICAS Y LOS AVATARES SOCIO-ECONÓMICOS

El desarrollo del cultivo del viñedo está ligado estrechamente a los condicionantes del medio natural. El clima, los suelos o el relieve son algunos de los elementos que más influyen en el desarrollo vegetativo de esta planta.

La distribución por el territorio se ha llevado a cabo teniendo en cuenta estos aspectos así como los factores históricos que han tenido lugar en estas tierras y que han ido modificando ligeramente la situación de los viñedos en la región.

\section{Las fuertes oscilaciones térmicas y la escasa calidad de los suelos}

Los factores ambientales constituyen un elemento que limita la actividad agrícola, siendo el clima, en el caso de los viñedos, el principal factor que condiciona el cultivo de la vid.

\footnotetext{
${ }^{1}$ Huetz de Lemps los denominó complejo viñedo-bodega (Huetz de Lemps, 2005).
} 
Durante muchos años las vides se han localizado en los suelos que no eran aptos para otros cultivos como las laderas de los páramos o los sectores con mayor pendiente. La vid es una planta que se adapta fácilmente a todo tipo de suelo y no es muy exigente en lo que respecta a la calidad de los mismos. La impronta que ha adquirido esta actividad en la D.O. Cigales en las dos últimas décadas ha dado lugar a la expansión del cultivo por todo el territorio en terrazas fluviales, glacis, laderas, superficies llanas, etc.

Los suelos de la comarca son del Mioceno y están formados por sedimentos del terciario y del cuaternario, predominando los materiales calizos, gredas yesíferas y arenas que reposan sobre arcillas y margas. Carecen de pedregrosidad y poseen una estructura granular débil sin materia orgánica.

La distribución ha tenido lugar en los cuatro niveles de terrazas que se distinguen en la margen derecha del río Pisuerga — $97,66 \%$ de la superficie- dando lugar a un mosaico de cultivos en el que se alternan el trigo, la remolacha, el maíz, el girasol o la cebada, entre otros. Mientras tanto, en la margen izquierda predominan los cultivos de regadío de la vega del Pisuerga para pasar después a los cereales que llegan hasta la superficie del páramo de Cerrato. En este sector el viñedo aparece como un cultivo marginal muy disperso por el territorio.

El clima es el mayor condicionante del viñedo en este sector. Se caracteriza por ser Mediterráneo de interior con irregularidad en las precipitaciones, elevadas oscilaciones térmicas y abundancia de nieblas y de heladas. Las precipitaciones totales en el área de estudio se sitúan entre los 400-450 mm anuales distribuidos entre 90-100 días y posee una temperatura media de unos $11,9^{\circ} \mathrm{C}$. La media anual de horas de sol es de 2.600 obteniendo el máximo en el mes de julio con unas 350-400 horas y el mínimo en diciembre, con menos de 100 horas.

Los inviernos se caracterizan por ser fríos y secos con temperaturas negativas, en algunas ocasiones de hasta $7^{\circ} \mathrm{C}$ bajo cero, frente a los veranos que suelen ser secos y muy calurosos superando varios días los $35^{\circ} \mathrm{C}$, por lo que las oscilaciones térmicas anuales pueden superar los $40{ }^{\circ} \mathrm{C}$ (Anuario de Agroclimatología de España, 1977).

Pero el clima posee una influencia importante en la vid con efectos muy diversos dependiendo de la estación en la que nos encontremos, de esta forma, los diferentes tipos de tiempo que se van sucediendo a lo largo del año ayudan a obtener la perfecta maduración alcohólica de las uvas proporcionando al fruto y a la planta las características necesarias para ser recogidas en la vendimia.

Su posición estratégica muy cerca de Valladolid ha sido uno de los factores más importantes en la expansión de esta comarca como un espacio vitiviní- 
cola emergente desde la Edad Media hasta la actualidad. Ha sido una zona de paso entre el centro peninsular y la cornisa Cantábrica por lo que fue recorrida por comerciantes, viajeros y trajineros entre otras personas que han podido conocer el vino que se elaboraba en estas tierras, transportándolo a otros rincones de España y dándolo a conocer a un público cada vez más amplio.

Aunque existen datos de la producción de vino en la comarca desde el siglo x, la época de mayor esplendor comienza a partir del siglo XVII con la instauración de la Corte de Felipe III en Valladolid extendiéndose hasta la invasión de la filoxera a finales del siglo XIX. A lo largo de todos estos años la historia vitivinícola de Cigales ha sufrido una serie de altibajos hasta que se produjo su nombramiento como D.O. a finales del siglo xx.

La impronta de la industria del vino en el territorio de Cigales: desde sus orígenes hasta la conformación de la D.O.

La evolución histórica de la comarca vitivinícola de Cigales no puede analizarse ni entenderse, si no se tiene en cuenta lo ocurrido en el conjunto regional y nacional a lo largo de la historia pero con especial énfasis en lo acaecido en los siglos XVIII, XIX y XX.

Los restos arqueológicos relacionados con el banquete aparecidos en algunos yacimientos de la región reflejan las primeras evidencias del consumo de vino. El posible origen de la viticultura en Castilla y León se remonta a la llegada de los Vacceos a la Cuenca del Duero en los siglos vil a. C. y v a. C. como demuestran los restos de ajuares encontrados en el yacimiento de Pintia, en la localidad de Padilla de Duero, en el municipio vallisoletano de Peñafiel (Sanz Mínguez, 2009). Desde este momento el consumo y el cultivo del vino se fue generalizando por toda la región alcanzando gran esplendor con la llegada de los romanos a la Península entre los siglos III y II a. C.

La gloria de este cultivo terminó en el siglo v. d. C. con las invasiones de los Suevos, los Vándalos y los Visigodos entre otros pueblos. Estos últimos permanecieron en la península hasta el 711 momento en el que desembarcaron las tropas árabes y comenzaron a conquistar el territorio peninsular. En el 728 los árabes sufrieron una batalla clave en Covadonga lo que les impidió terminar de conquistar toda la Península (Valdeón, 2006). A partir de entonces comenzó la Reconquista cristiana que tuvo un papel muy importante en la Cuenca del Duero fijando población a través de la puesta en marcha de tierras destinadas al cultivo, con especial incidencia de los viñedos, utilizando el sistema de presura y la plantación de viñas a medias que permitieron configurar 
grandes centros de producción de vino como la Tierra de Medina, el Valle del Duero vallisoletano y burgalés, y con menor intensidad, la comarca de Cigales.

Fue a partir de este periodo cuando comenzaron a aparecer mayores referencias de los viñedos del entorno de Cigales. Si bien, es cierto, que ya en el siglo $\mathrm{x}$ aparecen propietarios de viñedos en los municipios de Conforcos —actual Corcos del Valle-, y Covellas — actual Cubillas de Santa Marta-.

La actividad repobladora tuvo en la Iglesia su principal aliada para restablecer la población en el entorno del valle del Pisuerga en los monasterios de San Isidro de Dueñas o Santa María de Palazuelos en Corcos. El cultivo del viñedo era considerado un elemento clave en el proceso de repoblación. Desde la plantación de las viñas hasta obtener los primeros frutos podían transcurrir hasta cinco años por lo que la población tenía que permanecer en la villa para rentabilizar el cultivo. A la actividad religiosa se sumó la nobiliaria, muy arraigada en este territorio, que a partir del siglo xv comenzó a adquirir mayor peso gracias a la edificación de imponentes castillos como el de los Robles de Guevara en Trigueros del Valle o el de Fuensaldaña mandado construir por la familia Vivero; palacios como el de los Condes de Buendía en Dueñas o el de los Vizcondes de Mendoza en Valoria la Buena. Esta importancia nobiliaria y religiosa fue fundamental para la expansión del cultivo del viñedo ya que el consumo del vino entre estos estratos sociales era muy elevado.

El cultivo de la vid experimentó un fuerte crecimiento entre los siglos XVI y XVII en los municipios de la margen derecha del Pisuerga que preocupó a las autoridades ya que las vides relegaron a un segundo plano a cultivos como los cereales, los frutales y los propios bosques. Esta abundancia de vino permitió la exportación de estos caldos a las regiones del norte de la Península, que apreciaban el vino de Cigales, así como a algunos municipios de la provincia de León.

Este aspecto queda reflejado en los diferentes relatos de los viajeros europeos de los siglos XVIII y XIX, principalmente franceses como Gautier, Laborde, Merimée o Teste e ingleses como Twiss, Ford, Townsend, pero también holandeses como Cock, italianos como Guicciardini o Baretti (Plasencia, 1995) e incluso de los propios españoles como Ponz.

En estos manuales los viajeros se ocupaban de narrar los aspectos culturales, económicos y sociales del país. En los diferentes viajes que realizaron por la Península relataron aspectos del sector vitivinícola con especial incidencia de los territorios de la actual Castilla y León, Valdepeñas en la Mancha, los vinos de Jerez y Málaga en Andalucía y los de Rioja.

Generalmente la impresión que despertaban los vinos españoles a los viajeros extranjeros eran la de unos caldos de gran calidad pero producidos en mu- 
chas ocasiones de forma tosca. En sus recorridos estos viajeros describían de forma minuciosa los diferentes paisajes vitivinícolas que atravesaban, la forma de recolección y elaboración de vino y su comercialización fuera de la región (Plasencia, 1995). Así algunos autores decían del entorno de Tordesillas «La comarca desta villa es abundante de todas cosas necesarias á la vida humana, de pan, muchos y buenos vinos que se sacan para Viscaya y las montañas,...» (Cock, 1897, p. 19) o de Benavente «... un llano y fértil campo, pródigo en viñedos y cereales» (Münzer, 2002, p. 211). Respecto a la comarca de Cigales casi todos los autores destacan su posición estratégica en el entorno de la ciudad de Valladolid y una excelente calidad de los caldos.

Las citas más numerosas de estos viajeros en esta comarca hacen referencia a la peculiaridad de las bodegas que existían en estos municipios y que constituían barrios anexos a la trama urbana tradicional. Teste observa en Dueñas que las bodegas se entremezclaban con las propias casas cueva excavadas en la roca del promontorio donde se asentaba la ciudad y comenta que «en la colina hay unos agujeros que se cierran con zarzas. Supuse que estos agujeros daban acceso a las bodegas...» $(1959$, p. 42). Otra cita es la del francés Gautier que describiendo su estructura decía que estaban «cavadas en la roca viva, reciben la ventilación por torrecillas de forma de turbante, que ofrecen un falso aspecto de minarete muy singular» (recogido en Figueroa y Melgar, 1997, p. 246).

Uno de los cambios más significativos que sufrieron los viñedos de Castilla y León y de todo el conjunto de España fue la llegada de las diferentes plagas como el oídio, mildeu, pero sobre todo de la temida filoxera. Esta última enfermedad llegó en un primer momento a Inglaterra y Francia procedente de América y posteriormente a la Península Ibérica. La llegada de este parásito al viejo continente se remonta a 1863 en unos invernaderos cerca de Londres expandiéndose en 1865 a la región francesa de Orange (Provedo, 1987). Desde este momento se fue extendiendo por todo el país galo hasta arrasar por completo su superficie de viñedo. Los franceses tuvieron que recurrir a los caldos españoles para poder satisfacer su demanda y de esta forma el viñedo español vivió su época dorada con un incremento muy importante de su superficie con más de 500.000 nuevas has en apenas veinte años siendo Valencia, Cataluña, la Mancha, el valle del Ebro y Castilla los espacios que más atrajeron a los viticultores franceses para realizar sus inversiones y establecer su método de elaboración bordelés que permitiera satisfacer los refinados paladares que tenían los ciudadanos franceses.

Esta situación de bonanza se mantuvo hasta la entrada del insecto en la Península en el último tercio del siglo XIX por tres focos distantes entre sí: Málaga, Oporto y Gerona. Los dos primeros como consecuencia de la importación de 
pies americanos y el último tuvo lugar, por la invasión natural de la filoxera a través de Francia por el Roselló y los Pirineos Orientales (Piqueras, 2005).

Los viñedos castellanos se vieron afectados por el foco portugués que apareció en Gounvinhas, cerca de Oporto, y que se fue propagando por los viñedos del Duero portugués hasta entrar en España por el Miño hacia Galicia y por el Duero hacia Castilla. Los cultivos de vid de la región se vieron seriamente afectados, sobre todo los de las provincias de Valladolid y Zamora, con una destrucción de más del 50\% de su viñedo original, por lo que los tradicionales majuelos castellanos fueron sustituidos por cultivos de cereal acrecentando la imagen de Castilla como la región triguera por excelencia. La superficie en Castilla pasó de las 387.689 has en 1857, antes de la invasión filoxérica, a las 264.372 has en 1889 cuando la plaga había afectado a sus viñedos (Huetz de Lemps, 2005).

A lo largo del siglo xx se vivió un periodo de alti-bajos en la producción con una caída muy brusca en la comarca en los años sesenta motivada por el fenómeno del éxodo rural que asoló al conjunto español pero de forma especial a Castilla y León. Se produjo un abandono masivo de los campos y con ello de los viñedos. No fue hasta comienzos de los años ochenta cuando el sector vitivinícola comenzó a resurgir de sus cenizas expandiéndose de forma considerable gracias a los primeros nombramientos de D.O. que se produjeron en la región y que han constituido un gran impulso para recomponer la industria del vino en Castilla y León.

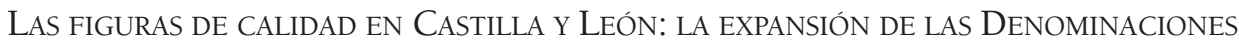
DE ORIGEN EN EL ÁMBito Vitivinícola

El sector agroalimentario de Castilla y León constituye uno de los pilares esenciales en el tejido económico regional además de contribuir en el desarrollo rural.

La variedad de estos productos es muy amplia y engloban hasta un total de 252 artículos (Molinero Hernando et al, 2001). De este conjunto de productos 54 poseen alguna figura de protección, véase: Denominación de Origen (D.O.), Indicación Geográfica Protegida (I.G.P.) o Marca de Garantía (M.G.) entre otras (Portal de la Junta de Castilla y León a fecha de 2012). Dentro de estos productos son las carnes y los vinos los que presentan el mayor número de figuras de calidad con un total de 16 y 13 respectivamente, seguidos de las frutas y las hortalizas con ocho productos, los quesos y las legumbres con cinco cada uno, cuatro para productos de panadería y repostería, además del aceite de oliva del Noroeste, la agricultura ecológica y la producción integrada de Castilla y León. 
Según el Reglamento CE 510/2006 del Consejo de 20 de marzo de 2006 sobre la protección de las indicaciones geográficas y de las denominaciones de origen de los productos agrícolas y alimenticios se define Denominación de Origen como «el nombre de una región, de un lugar determinado o, en casos excepcionales, de un país, que sirve para designar un producto agrícola o un producto alimenticio». Los productos deben de ser de dicha región y su producción, transformación y elaboración se tiene que realizar en la zona geográfica delimitada. El objetivo prioritario es defender los intereses de los productores en concreto y garantizar la calidad de lo que se consume a los propios consumidores (De la Calle Robles, 2002).

Siguiendo estos criterios existen en Castilla y León un total de nueve D.O. que han ensalzando a esta región a lo más alto del sector vitivinícola además de tener otras zonas productoras de vino (figura 2).

FIGURA 2

FIGURAS DE CALIDAD DE PRODUCTOS VITIVINÍCOLAS EN CASTILLA Y LEÓN

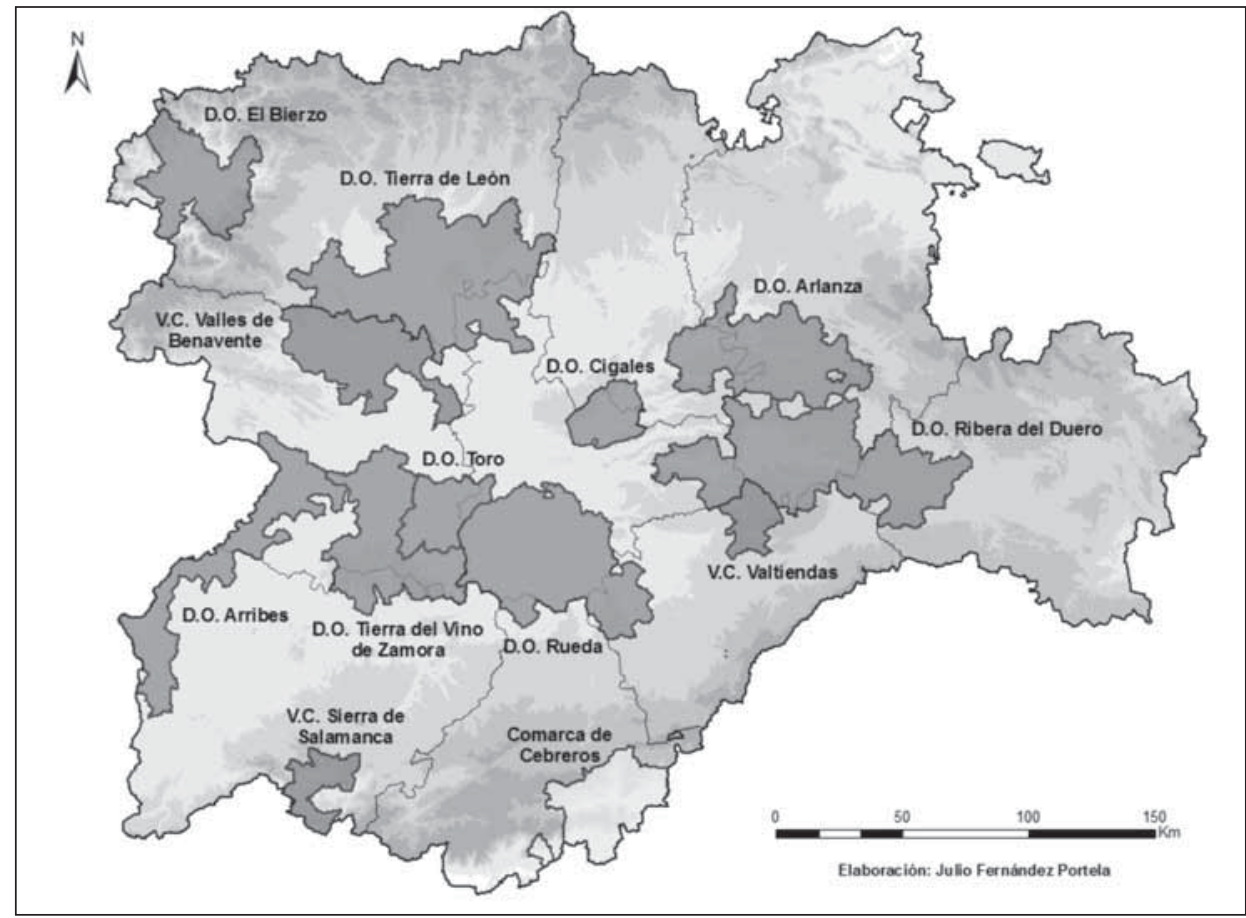

Fuente: elaboración propia a partir de los reglamentos de las diversas figuras. 
La historia de las D.O. en la región es muy reciente y se remonta a los últimos treinta años. La primera D.O. que se estableció en la región fue la de Rueda a través de una Orden del Ministerio de Agricultura el 12 de enero de 1980. Desde ese año se han ido sucediendo una serie de nuevos nombramientos en otras comarcas de fuerte tradición vitivinícola como la Ribera del Duero en 1982, Toro en 1987, el Bierzo en 1989 y Cigales en 1991. En poco más de diez años se tejió el entramado de una industria agroalimentaria que ha sido y es el soporte de muchas áreas rurales.

Hasta 2007 no se volvió a producir ningún nuevo nombramiento de D.O. En este año se incorporaron a la lista regional cuatro nuevos espacios véase: Tierra de León, Arribes, Arlanza y Tierra del Vino de Zamora.

Finalmente hay que mencionar un conjunto de áreas productoras que cuentan con otras figuras de protección como es la Indicación Geográfica Protegida (I.G.P.) de los vinos de la Tierra de Castilla y León, y otros tres espacios vitivinícolas amparados bajo la mención de «Vinos de Calidad» como son Valtiendas, Valles de Benavente y Sierra de Salamanca. A estos espacios hay que añadir la comarca vitivinícola de Cebreros, al Sur de Ávila, así como el resto de viñedos esparcidos por todo el territorio regional dando lugar a una superficie total de 75.874 has en la región en 2011.

La apuesta por la calidad y la promoción han sido los principales objetivos de las D.O. Son un instrumento para el desarrollo local y regional porque potencian un producto que solo se elabora en una zona determinada y ayudan a difundir la comercialización del mismo más allá del ámbito local traspasando fronteras (Molleví, 2001).

Como se puede comprobar Castilla y León se está orientando hacia la producción de caldos de mayor calidad. La expansión que han experimentado las diversas D.O. ha sido muy importante pero con mayor intensidad en los casos de Ribera de Duero, Rueda, Toro y Cigales. Ha sido esta última la elegida para analizar las transformaciones paisajísticas, económicas, sociales y culturales que se han producido en los diferentes municipios que la conforman con un crecimiento importante de la superficie de viñedo, así como profundos cambios urbanos derivados de su cercanía a la capital vallisoletana.

CAMBIOS EN LA INDUSTRIA VITIVINÍCOLA: TRANSFORMACIONES ECONÓMICAS Y PAISAJÍSTICAS

El nombramiento de Cigales como D.O. se aprobó el 9 de Marzo de 1991 por orden del Ministerio de Agricultura, Pesca y Alimentación. Desde enton- 
ces se ha ido consolidando como una zona productora de vinos de calidad a la vez que se han ido produciendo grandes inversiones para modernizar todo el sistema productivo apareciendo nuevas instalaciones que han incrementado la comercialización de los vinos. Estas transformaciones han provocado una serie de cambios en el paisaje tradicional consolidando a la industria vitivinícola como un elemento vertebrador del territorio.

\section{El aumento de la superficie del viñedo en el conjunto de la D.O. Cigales}

La evolución de la superficie de viñedo en los municipios que componen la comarca de Cigales ha sido positiva. En poco más de veinte años casi se ha duplicado la superficie pasando de 1.735 has a 3.437 has. De este conjunto $2.217,18$ has se encontraban inscritas en la D.O. Cigales a fecha de 8 de agosto de 2011, el resto no pertenecían a ella (datos facilitados por la D.O. Cigales).

En la figura 3 se puede observar la tendencia que ha seguido el incremento de la superficie. Se distinguen dos periodos clave. Por un lado se observa un

\section{FIGURA 3}

\section{EVOLUCIÓN DE LAS HAS DE VIÑEDO EN LA COMARCA DE CIGALES}

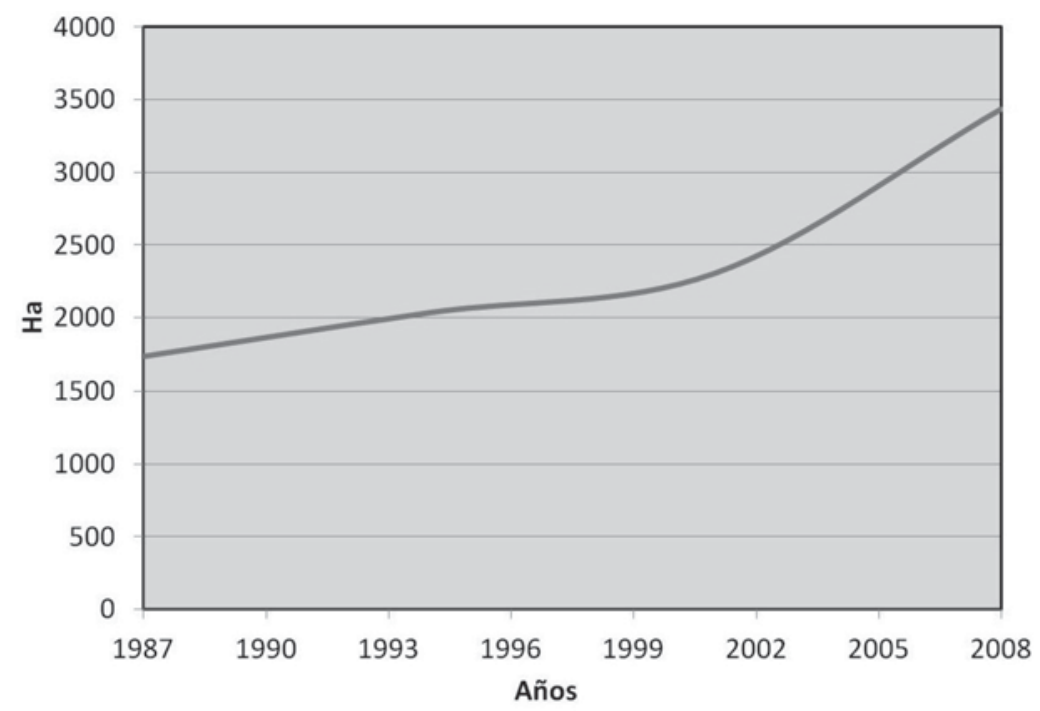

Fuente: elaboración propia a partir de Documentos 1 T de la Junta de Castilla y León (JCyL). 
ligero crecimiento de un $17 \%$ en los años previos a su constitución. En este periodo se volvieron a replantar antiguos majuelos que habían sido arrancados o se habían dejado de cultivar. Los viticultores vieron en la D.O. una salida a la crisis que había vivido la vid desde los años sesenta y decidieron invertir de nuevo en este cultivo sopesando las facilidades que podrían obtener al ampararse a una figura de calidad de esta magnitud.

Sin duda alguna el segundo periodo de crecimiento (2001-2008) ha sido más intenso con un aumento de casi el 50\%. Las plantaciones se volvieron a esparcir por el territorio regional aunque nunca volvieron a llegar a las cifras existentes antes de la invasión de la filoxera. En esta ocasión se fue enfocando hacia la producción de caldos de mayor calidad al igual que había ocurrido en otras D.O. dentro y fuera de la región.

Las diferentes políticas vitivinícolas que se han ido sucediendo con el paso de los años han ido configurando un sector clave para la economía regional al otorgar ayudas a la restructuración y replantación del viñedo, a la formación de nuevos viticultores y nuevos empresarios o a la reconversión varietal. El principal objetivo era mejorar la competitividad de los diferentes productores de Cigales para poder comercializar los vinos en el mercado regional, nacional e internacional adaptando este producto a la nueva demanda que había en el mercado. De esta forma se produjo un cambio transcendental en la industria. Se fueron instalando grupos multinacionales que compraron derechos a pequeños viticultores que habían decidido arrancar sus viñedos, así como otros que vieron una buena oportunidad para jubilarse y venderlos a buen precio. La presencia de grandes bodegas continuo en aumento y algunas de las explotaciones de vides fueron a parar a manos de estas bodegas que carecían de viñedos viejos plantados en vaso.

El primero de estos grandes grupos que se estableció en la D.O. fue Frutos Villar en el municipio de Cigales en 1960 mucho antes del nombramiento como D.O. Pero fue a partir de 1991 cuando comenzó su política de expansión adquiriendo nuevos viñedos en los diferentes municipios de la comarca. La Bodega Valdelosfrailes en Cubillas de Santa Marta perteneciente al Grupo Matarromera y Bodegas Museum en Cigales perteneciente al Grupo Varón de Ley constituyen otros de los ejemplos más significativos de la instalación de grandes bodegas en este territorio con presencia en otras D.O. como Ribera del Duero, Rueda, Toro o la D.O.Ca. Rioja siguiendo el mismo modelo ocurrido en otros espacios vitivinícolas. Rueda es un ejemplo con la instalación de la bodega riojana Herederos de Marqués de Riscal bajo la razón social Vinos Blancos de Castilla S.A. en 1972 (Sánchez Hernández, 2002). 
Otros viticultores decidieron continuar con el negocio y realizaron inversiones para ampliar sus instalaciones a través de la compra de maquinaria y de nuevos viñedos. Las bodegas familiares que han permanecido elaborando sus propios vinos se han adaptado a las exigencias del mercado y han ido modernizando sus instalaciones como ha sucedido con Bodegas Alfredo Santamaría en Cubillas, Bodegas Remigio Salas en Dueñas, Bodegas Hijos de Félix Salas en Corcos o la Bodega La Legua en Fuensaldaña.

Estos cambios han modificado el paisaje de forma considerable. Han aparecido numerosas explotaciones de vides con nuevos sistemas de plantación en espaldera que van adquiriendo poco a poco mayor representatividad $-25 \%$ del total de la superficie de viñedo- aunque todavía las plantaciones en vaso siguen teniendo el mayor peso en esta D.O. Con este nuevo sistema se ha podido mecanizar una parte de la vendimia ahorrando costes en la mano de obra. Antes la recogida de la uva la realizaban las personas de los propios pueblos o de los alrededores con el tranchete y la uva que cortaban la depositaban en unos conachos de mimbre. Ahora los majuelos se caracterizan por la presencia de grandes máquinas que recogen la uva y las personas que todavía trabajan en la recolección suelen ser de Europa del Este en su mayoría.

Los rendimientos que se obtienen de las plantaciones en espaldera son mayores que los obtenidos, en las de vaso pero las grandes bodegas se están interesando en obtener majuelos con cepas viejas - a poder ser centenarias-, ya que la calidad de la uva que obtienen es mayor y la utilizan para elaborar vinos tintos de crianza y reserva que están adquiriendo gran fama en la actualidad.

El paisaje ha cambiado en el conjunto de la comarca pero no se ha producido con la misma intensidad en todos los municipios. Han sido los localizados en la margen derecha del Pisuerga los que han experimentado las mayores transformaciones paisajísticas y económicas al soportar la mayor expansión de este cultivo.

La dicotomía de los viñedos de la margen derecha del Pisuerga frente a los de la margen izquierda

El desarrollo del cultivo del vino se ha llevado a cabo a lo largo de la margen derecha del río Pisuerga (figura 4). Han sido los municipios de Cigales, Cubillas, Mucientes, Corcos, Trigueros y Fuensaldaña los que han experimentado la máxima expansión de la vid con el 99\% del crecimiento total con 1.685 de las 1.702 nuevas has entre 1987-2008. 
Los casos más espectaculares han sido los de Cubillas con un incremento del $263,43 \%$ y 366 nuevas has, Trigueros con un $182,22 \%$ y 164 has y Corcos con un 168,21\% y 291 has. En cifras absolutas ha sido el municipio de Cigales - que partía con los datos más elevados- el que ha aumentado más su superficie con 495 has alcanzando la cifra total de 1.065 en el año 2008 siendo el municipio con mayor extensión - 30.98\% del total de viñedo de la comarca-

Esta desigual evolución se puede observar en los diferentes cartogramas elaborados a escala municipal para los cuatro años de análisis. Entre 1987 y 2008 se ha ido configurando un sector con una presencia de la vid muy importante en la margen derecha del río Pisuerga frente a los municipios de la margen izquierda como Cabezón, Valoria, San Martín o Santovenia donde el crecimiento ha sido muy pequeño y en algunos casos inexistente (figura 4).

FIGURA 4

EVOLUCIÓN DE LA SUPERFICIE DE HECTÁREAS DE VIÑEDO

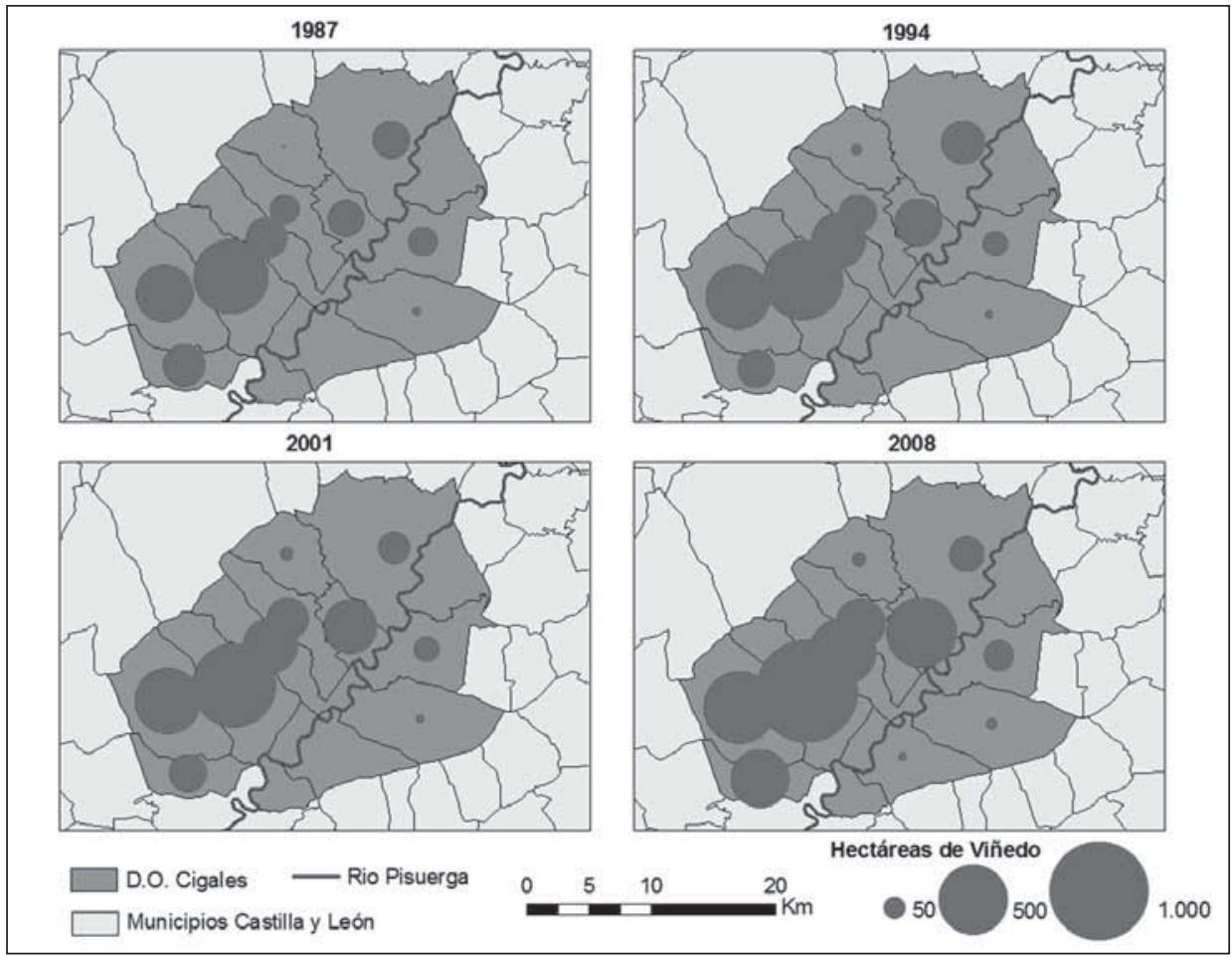

Fuente: elaboración propia a partir de Documentos 1 T de la Junta de Castilla y León (JCyL).

Estudios Geográficos, Vol. LXXIII, 272, pp. 63-90, enero-junio 2012 ISSN: 0014-1496, eISSN: 1988-8546, doi: 10.3989/estgeogr.201203 
Han sido dos las razones más importantes que han originado esta localización pero que se encuentran encadenadas la una con la otra. La primera de ellas se debe al fuerte peso histórico del cultivo de la vid en este sector. Desde sus orígenes los viñedos se han localizado en estos municipios y han respetado en la actualidad este emplazamiento privilegiado. Este hecho ha dado lugar a que se produzcan grandes inversiones a cargo de viticultores locales y foráneos instalando los nuevos complejos vitivinícolas en este lado del río. La cercanía a los viñedos constituía un atractivo para las nuevas bodegas industriales que han intentado imitar el modelo francés de Chateau localizando en el entorno de la bodega sus propios viñedos. Los ejemplos más característicos son los que se han producido en el municipio de Cubillas de Santa Marta con las Bodegas Valdelosfrailes y Santa Rufina.

De esta forma se ha ido originando un paisaje vitivinícola de fuerte arraigo entre la población constituyendo un elemento clave para su economía a la vez de un símbolo distintivo entre otros municipios de la región incrementándose la superficie a costa de los cereales.

La imagen de Castilla se caracteriza por la de ser una tierra destinada al cultivo del cereal conocida como el «granero de España». En este sector la actividad cerealística posee un peso muy importante y es uno de los pilares esenciales en la economía rural de los agricultores. A pesar de esta impronta la superficie de viñedo ha ido arañando terrenos al cereal representando en algunos municipios un peso muy importante en el sector agrícola. Sin duda alguna el caso más llamativo es el de Cubillas que ha pasado de representar el 7,45\% de la superficie cultivada en 1987 al 31,84\% en 2008 (figura 5). En este municipio se han llevado a cabo grandes inversiones en lo concerniente a la mejora de las explotaciones, así como la construcción de nuevas bodegas, ensalzando a Cubillas como uno de los lugares más emblemáticos de la D.O. Cigales junto con el propio Cigales con el 22,85\% y Fuensaldaña con el 18,90\%.

Este incremento de la superficie de vides ha tenido consecuencias directas sobre la estructura de las bodegas. Ante el incremento de la producción de uva y de la elaboración de vino, las bodegas subterráneas tradicionales no podían hacer frente a la nueva cantidad que tenían que elaborar de estos caldos, por lo que en los últimos veinte años se ha producido una expansión de las nuevas bodegas, la gran mayoría en forma de naves industriales, que han permitido elaborar mayor cantidad de vino además de poseer los medio más modernos para su elaboración y conservación, adecuando sus instalaciones a las exigencias impuestas por las normativas sanitarias en este sector. 
FIGURA 5

PORCENTAJE DE LA SUPERFICIE DEL VIÑEDO RESPECTO AL TOTAL CULTIVADO

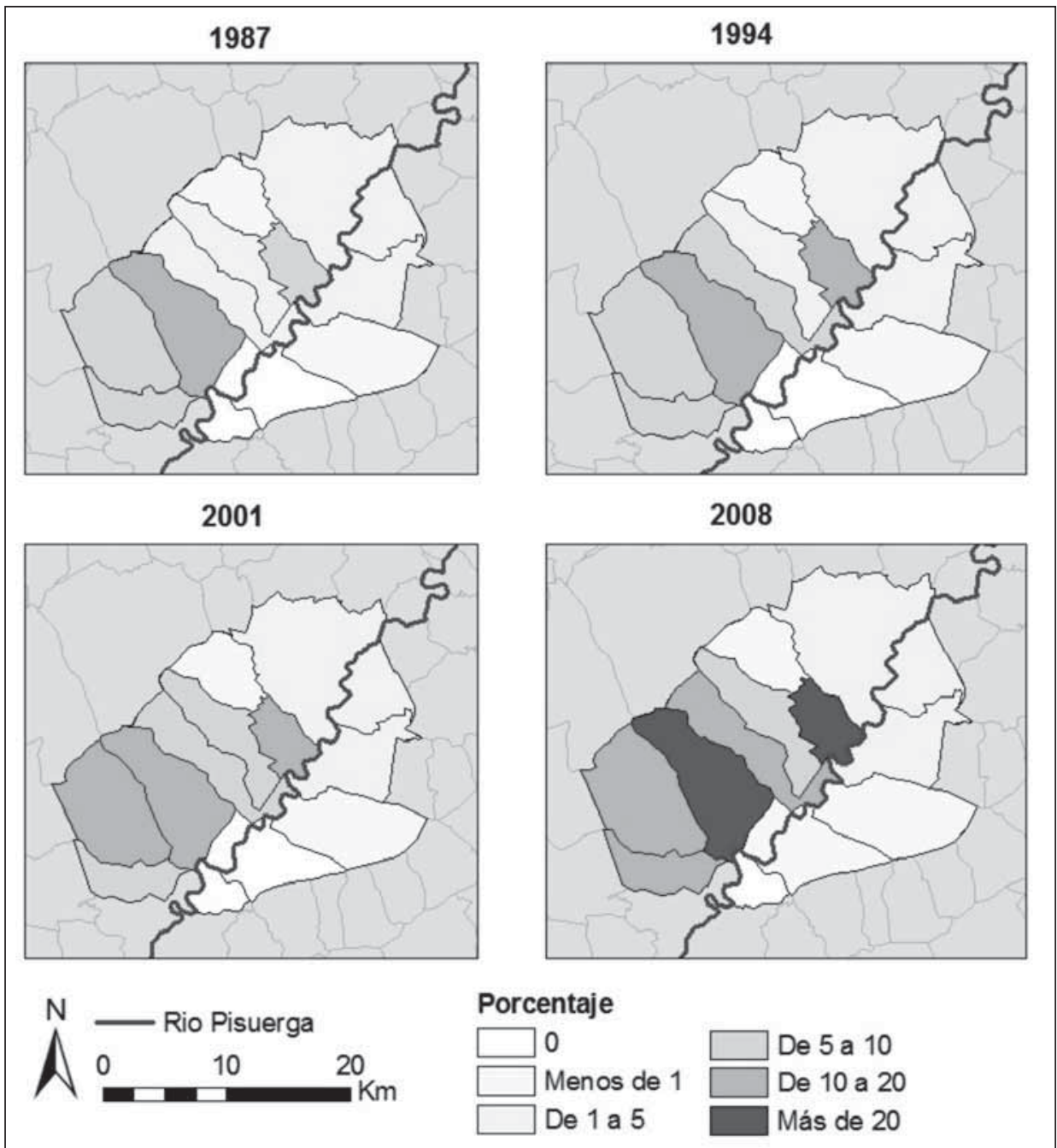

Fuente: elaboración propia a partir de Documentos 1 T de la Junta de Castilla y León (JCyL). 
EL CAMBIO DE LA BODEGA TRADICIONAL A LA INDUSTRIAL: DE LA CONCENTRACIÓN EN BARRIOS A LA DIFUSIÓN POR EL TERRITORIO

Al igual que la superficie cultivada las bodegas han sufrido una serie de cambios de gran relevancia tanto en su arquitectura como en el ámbito económico y social.

Existen bodegas en las que se elabora el vino de forma tradicional y en pequeñas cantidades frente a los nuevos complejos vitivinícolas de grandes dimensiones y con la tecnología más avanzada en el proceso de vinificación que producen vino en cantidades industriales destinado principalmente a un nuevo mercado a nivel provincial y regional, pero que cada vez se ha ido vendiendo más a una escala nacional e internacional.

En total existen en la D.O. 512 viticultores y se encuentran inscritas 33 bodegas (Consejo Regulador, 2012). La mayor parte de estos viticultores poseen pequeñas bodegas tradicionales que han obtenido generalmente por herencia donde elaboraban el vino que consumían o vendían a sus personas más allegadas. Hoy día este sistema ha cambiado por completo, ya que el vino, generalmente, se elabora en las nuevas bodegas industriales localizadas principalmente en Mucientes, Cubillas y Cigales (figura 6).

\section{FIGURA 6}

NÚMERO DE BODEGAS INSCRITAS EN LA D.O. CIGALES

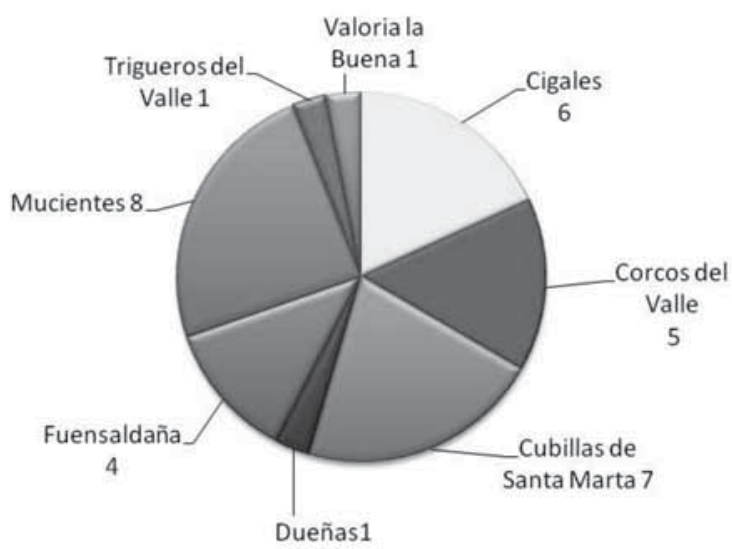

Fuente: elaboración propia a partir de datos de www.do-cigales.es. 
A pesar del papel que juegan a día de hoy las nuevas bodegas en la industria vitivinícola no se debe olvidar el papel que han tenido y tienen las bodegas tradicionales. Durante muchos siglos, y en concreto entre el XIV y hasta el último tercio del xx, consiguieron elaborar excelentes caldos que vendían en la ciudad de Valladolid así como en la Cornisa Cantábrica permitiendo forjar un nombre a la comarca de Cigales que sigue perdurando en la actualidad.

Su distribución en el territorio seguía una lógica espacial determinada concentrándose en barrios propios anexos al municipio como en Cubillas y $\mathrm{Mu}$ cientes, o muy cerca del mismo como en Corcos o Valoria la Buena.

\section{Los barrios de bodegas tradicionales anexos al núcleo urbano}

La expansión del cultivo del viñedo no solo ha transformado el campo vitivinícola. El crecimiento de la superficie de vides ha ido parejo a un desarrollo muy importante en la proliferación de nuevas bodegas industriales que han salpicando el territorio de la D.O. Hasta finales de la década de los ochenta el conjunto de Cigales se caracterizaba por la existencia de barrios de bodegas anexos al municipio donde se llevaba a cabo todo el proceso de vinificación.

Estas bodegas eran subterráneas y para su construcción se tenían que tener en cuenta una serie de aspectos. El más importante era la elección de un terreno apropiado que necesitaba «...la existencia de un subsuelo adecuado con una capa impermeable, compacta, homogénea y consistente de arcilla, margas o rocas calizas o yesíferas blandas, con un espesor superior a los diez o doce metros para que no existiese una capa freática. Todas estas características de suelo se presentan en casi todas las laderas o cerros pero no en los suelos llanos de terrazas de aluvión, en los que era necesario profundizar hasta encontrar suelos compactos [...] Por ello la mayoría de las bodegas están construidas en cuesta, ladera o cerro, siendo una de las características definitorias» (Franco et al., 2005, p. 143).

Una vez elegido el lugar se comenzaba a hacer un agujero que constituía la nave central y a partir del mismo se excavaban en el interior los diferentes compartimentos para albergar las diversas estancias. La arena que se extraía se depositaba en la parte superior dando forma a una especie de bóveda que servía como aislante proporcionando la temperatura adecuada para la fermentación y la conservación de los caldos. Finalmente se realizaban los vanos correspondientes a la puerta de entrada, la zarcera y el respiradero.

Estas construcciones han ido configurando un paisaje inconfundible en el bajo valle del Pisuerga con montículos de arena y unas especies de chimeneas 
conocidas como respiraderos cuya función era ventilar la bodega en periodos de vendimia expulsando al exterior un gas tóxico conocido como tufo (Fernández Portela, 2011).

Estos barrios han constituido en elemento fundamental en la vida social y económica de los habitantes de estos municipios. Además de ser un lugar destinado a la elaboración del vino, en las bodegas, se llevaban a cabo reuniones sociales con el objetivo de entablar conversaciones y comentar los pormenores de la vendimia así como otros asuntos de diversa índole.

A día de hoy muchas bodegas tradicionales han dejado de elaborar el famoso clarete de esta zona y conservan un papel socio-cultural. Muchas de ellas se han reformado y se han convertido en restaurantes, merenderos y museos.

El incremento de la producción de uva hacía imposible la elaboración del vino en estas bodegas tanto por su tamaño como por las incomodidades derivadas de sus obsoletas instalaciones y rudimentarias herramientas. Este aspecto originó la creación de nuevas bodegas de mayor tamaño dispersas por el territorio pero localizadas en los ejes de comunicación para facilitar el transporte del producto. De esta manera comenzaron a surgir por el campo grandes naves industriales de forma dispersa que fueron fraguando un nuevo paisaje vitivinícola y una nueva forma de elaborar el vino ya que con los estatutos de la D.O. Cigales el tradicional vino clarete dejó de elaborarse para producir el vino conocido como rosado.

\section{Los nuevos complejos vitivinícolas: las bodegas industriales}

La orientación en la industria vitivinícola que adquirió Cigales tras su nombramiento como D.O. dio lugar a una serie de grandes inversiones con el objetivo de remodelar y modernizar el entramado económico vitivinícola a través de la construcción de grandes bodegas capaces de producir cientos de miles de litros de rosado y de vinos tintos.

Estas nuevas bodegas, dispersas por el territorio y cercanas a los ejes de comunicación como la autovía o las carreteras comarcales, han hecho de Cigales un centro vitivinícola importante y un referente del rosado en la región y poco a poco en el conjunto nacional.

Aunque todas cumplen la misma función su tipología arquitectónica ha sido muy diversa alejándose de los grandes diseños vanguardistas realizados en otras D.O. por prestigiosos arquitectos como en la Ribera del Duero con las Bodegas Protos en Peñafiel diseñadas por Richard Rogers y Bodegas Portia en Gumiel de Izán por Norman Foster, o Ysios en La Guardia (D.O.Ca. Rioja) a cargo de Santiago Calatrava. 
En el caso de Cigales la enoarquitectura o arquitectura del vino no ha tenido el mismo peso que en otras áreas de producción de vino pero se pueden diferenciar tres estilos en su construcción.

Uno de ellos lo conforman aquellas bodegas que han intentando mantener cierta integración en el paisaje en el que se insertan y han utilizado materiales nobles como la piedra, el adobe, el ladrillo y la madera realizando una serie de construcciones típicas de este territorio siendo el caso más representativo la Bodega Alfredo Santamaría en Cubillas.

Por otro lado estarían las nuevas naves industriales, la gran mayoría de las bodegas de reciente construcción. En este tipo se puede hacer una distinción entre aquellas que son simples naves de hormigón y ladrillo sin ningún diseño como Bodegas Concejo en Valoria la Buena, Sinforiano Vaquero en Mucientes o Frutos Villar en Cigales, frente a otras cuyo objetivo es otorgar mayor distinción y elegancia a la bodega forrando las fachadas principales con piedra en un intento de adecuar la bodega al medio rural en el que se inserta como Bodegas Valeriano y Santa Rufina en Cubillas de Santa Marta.

Finalmente estarían las nuevas bodegas que han seguido unos criterios algo más vanguardistas en su diseño y han combinando materiales tradicionales como la piedra y el ladrillo con otros materiales como el mármol o el cristal surgiendo de esta forma edificios más atractivos como las Bodegas Museum e Hiriart en el municipio de Cigales.

Frente a estas nuevas construcciones muy pocas bodegas tradicionales siguen manteniendo sus antiguas instalaciones para la elaboración del vino en cantidades industriales. El ejemplo más significativo lo constituye la Bodega Remigio Salas en Dueñas que conserva la bodega tradicional como el centro principal de un complejo vitivinícola con largas galerías repletas de tinos de madera y de hormigón donde descansan los tintos que producen hasta que salgan al mercado.

Ante las nuevas exigencias sanitarias y el incremento de la cantidad de vino elaborada las nuevas instalaciones han ido incorporado modernos sistemas de producción y conservación de los caldos adquiriendo la maquinaria adecuada. De esta forma los depósitos de hormigón o las grandes cubas de madera que se encontraban en las bodegas subterráneas han sido sustituidos por grandes depósitos de acero inoxidable y poliéster que permiten controlar de forma más eficaz la temperatura del vino y llevar un control más estricto del producto. Además poseen modernos laboratorios, salas de catas, de reunión, comedores, salas de exposiciones, etc. que permiten realizar nuevas actividades siempre relacionados con el mundo del vino conocidas como enoturismo y que han contribuido a diversificar la actividad económica de este medio rural a través de la apertura de hoteles, casas rurales o restaurantes, muchos de ellos a cargo de las propias bodegas. 
LA DIVERSIFICACIÓN DE LA ECONOMÍA VITIVINÍCOLA A TRAVÉS DEL PAPEL DEL ENOTURISMO

La industria vitivinícola en la D.O. Cigales ha supuesto un impulso económico, social y cultural de gran envergadura y se ha consolidado como uno de los elementos más representativos del desarrollo rural de Castilla y León.

Las bodegas no solo elaboran y venden vino sino que han diversificado sus actividades y hoy día organizan eventos de todo tipo como congresos, comidas, exposiciones, etc. Las inversiones que se han llevado a cabo en los últimos veinte años destinadas a la creación de nuevas bodegas industriales y rehabilitación de las ya existentes han permitido habilitar espacios destinados a acoger eventos y otras actividades.

El enoturismo ha supuesto un valor añadido muy importante a este negocio aunque en el caso de Cigales no ha sido tan intenso como en otras D.O. como Ribera del Duero (Alvear González, 2007). La principal actividad que se realiza son las visitas guiadas a sus instalaciones y en ocasiones a los viñedos, seguidas de una degustación de su vino. También han habilitado salas de catas donde organizan cursos y congresos de temática vitivinícola, enológica y paisajística entre otros además de poseer grandes salones en los que organizan bodas y comidas de empresas.

Sin duda alguna ha sido el mundo de la restauración y la hostelería donde se han producido las mayores inversiones por parte de los propios bodegueros. Los ejemplos más representativos son el Centro de Turismo Rural Pago de Trascasas a cargo de Bodegas Alfredo Santamaría en Cubillas de Santa Marta y Hospedería Concejo en Valoria La Buena por parte de Bodegas Concejo. También es destacable la actuación llevada a cabo por Bodegas Lezcano Lacalle en Trigueros del Valle que ofrece la posibilidad de comer entre las barricas.

A estos establecimientos hay que sumar una red muy amplia de casas rurales y restaurantes que han ido apareciendo en los diferentes municipios y han creado un tejido turístico muy importante - desconocido hasta la fechacreando trabajo para los familiares de los propios bodegueros así como para personas de los diferentes municipios.

En total hay ocho casas de turismo rural, cuatro centros de turismo rural, otros siete alojamientos repartidos entre posadas, moteles, hostales y campings, y cuarenta seis restaurantes, todo ello distribuido por todos los municipios de la D.O. Cigales. De todos estos establecimientos han sido las casas rurales, los centros de turismo de rural, y algunos restaurantes los que han surgido asociados a la industria del vino y las iniciativas han sido planteados por los propios bodegueros como una nueva forma de promoción de sus vinos. 
Como valores añadidos hay que considerar la rica gastronomía de esta comarca, siendo el lechazo asado la especialidad; el abundante patrimonio Histórico-Artístico como San Isidro de Dueñas, el castillo de los Robles de Guevara en Trigueros del Valle, la iglesia de Santiago de Cigales, el Castillo de Fuensaldaña, las esclusas del Canal de Castilla o el Puente Romano de Cabezón de Pisuerga; así como otras actividades que se realizan en torno a la figura del vino como los conciertos de órgano con degustación de vino en Cubillas, el museo del Cántaro en Valoria la Buena o el Aula de interpretación del Vino en Mucientes.

Sin duda alguna uno de los mayores reclamos turísticos de esta comarca lo constituye la «Fiesta de la Vendimia» celebrada a finales de Septiembre en Cigales y que está declarada como Fiesta de Interés Turístico Regional. Durante la semana en la que tiene lugar esta celebración se organizan catas, conferencias sobre el mundo del vino, exposiciones de pintura, ferias gastronómicas, bailes y música tradicional que atraen a cientos de visitantes a degustar los famosos rosados de la comarca.

Todas estas actividades han ayudado a dinamizar un territorio agrario por excelencia que ha ido adaptándose a los nuevos tiempos y a la impronta del cultivo del viñedo colocando el nombre de Cigales entre las D.O. más representativas de Castilla y León a la vez que algunos de sus municipios se han ido configurando como el periurbano norte de la ciudad de Valladolid con una expansión urbanística que ha transformado de forma importante el paisaje agrario, y en concreto el vitivinícola, pero que a su vez ha contribuido a la expansión de este producto.

\section{CONCLUSIÓN}

Desde el nombramiento como D.O. pero sobre todo a partir del comienzo del siglo XXI la industria vitivinícola ha sufrido una serie de transformaciones muy importantes en la economía, en el paisaje y en el ámbito social y cultural del conjunto de los municipios que la conforman. Estas transformaciones derivan directamente de la expansión de la superficie de viñedo por las diferentes terrazas del Pisuerga que ha provocado un mayor peso de esta actividad en el territorio.

Estos cambios acaecidos no se han producido con la misma intensidad por todo el territorio. Han sido los situados en la margen derecha del Pisuerga, y en concreto Cigales, Cubillas y Mucientes los que han soportado prácticamente todo el crecimiento de la superficie del viñedo y los que han recibido las mayores inversiones para la instalación de las nuevas bodegas 
industriales y la adaptación de las ya existentes a la nueva demanda del mercado.

La industria vitivinícola ha generado cambios paisajísticos muy significativos en un espacio agrario tradicional muy característico para esta comarca. Las bodegas subterráneas se han ido sustituyendo por las grandes naves industriales dispersas por el territorio que en pocas ocasiones han sabido adaptarse al medio que las rodea, y permanecen como instalaciones fabriles en medio de los campos de trigo y de los viñedos. Hace poco más de treinta años, cuando se entraba a los pueblos por la carretera principal la primera imagen que se tenía del mismo era el campanario de la iglesia mientras que hoy día se observan los almacenes de cereales y las nuevas bodegas.

Las cepas en vaso van dejando paso a las plantadas en espaldera y los majuelos aparecen llenos de estacas de madera y alambres que permiten a la vid trepar lateralmente y a lo alto, lo que facilita la mecanización de la vendimia y que en estos espacios sea cada vez más frecuente la presencia de grandes máquinas vendimiadoras y menos personas cortando los racimos de uvas.

La gran expansión de las vides ha dado lugar a la elaboración de vino en mayor cantidad generando nuevos puestos de trabajo. Estos empleos no han sido solo en las labores del campo como la poda o la vendimia que poseen un carácter estacional y que pueden llegar a emplear cada año a más de 600 personas, sino que hay que tener en cuenta los empleos fijos compuestos por distribuidores, enólogos y diversos técnicos que trabajan en el interior de las bodegas y que se elevan a unas 150 personas. Además hay que añadir todo el personal que cada vez va siendo más numeroso destinado a las labores derivadas directamente del enoturismo como guías de bodegas, camareros, cocineros, regentes de casas rurales, etc. que superan las 50 personas.

Los cambios paisajísticos e industriales ocurridos en la D.O. Cigales han supuesto un aliento de aire fresco para la población que reside en estos lugares. La expansión de la industria ha permitido crear nuevos puestos de trabajo y en ocasiones mantener una parte de la población que llevaba saliendo del pueblo hacia la ciudad desde los años sesenta. En menor medida ha permitido el asentamiento de nuevos pobladores que han abierto algún negocio derivado del enoturismo y han decidido establecer su residencia en el municipio. A pesar de todo la mayor parte de los propietarios de estos negocios realizan la gestión desde la ciudad o se desplazan a diario a su lugar de trabajo sin mantener otro vínculo con el municipio.

La apertura de las bodegas y los nuevos eventos organizados por las mismas han permitido dinamizar un territorio que se caracterizaba por la intensidad de la actividad agraria y que gracias a este fenómeno se ha diversificado 
surgiendo nuevas actividades que atraen a turistas de diferentes partes de la geografía española y europea consolidándose como uno de los motores de la economía y de desarrollo rural de esta comarca extrapolándose a otros espacios vitivinícolas de la región.

Recibido: 31/08/2011

Aceptado: 25/04/2012

\section{BibLiografíA}

Alonso Santos, J. L. (2003a): "Redes y procesos de innovación en las comarcas vinícolas de Castilla y León: el ejemplo de la D.O. Bierzo". BAGE, 36, pp. 43-60.

Alonso Santos, J. L.; Aparicio Amador, L. J. y Sánchez Hernández, J. L. (2003b): "Los espacios vitivinícolas en Castilla y León: la evolución hacia un sistema productivo de calidad". BAGE, 35, pp. 101-122.

Alonso Santos, J. L.; Aparicio Amador, L. J. y Sánchez Hernández, J. L. (2005): "El entorno de servicios públicos y privados a la industria vinícola de Castilla y León", en F. Manero y H. Pascual (coords): Innovación tecnológica, servicios a las empresas y desarrollo territorial. Valladolid, Universidad de Valladolid.

Alvear González, A.; Aparicio Castrillo, S. y Landaluce Calvo, M. I. (2007): "Una primera exploración del mercado enoturístico real de la Ribera del Duero", en J. C. Ayala Calvo (coord.): Conocimiento, innovación y emprendedores: camino al futuro. La Rioja, Universidad de la Rioja.

Aparicio, J.; Sánchez, J. L.; Alonso, J. L. y Rodero, V. (2008): "La Ribera del Duero, geografía de un medio innovador en torno a la viticultura". Scripta Nova, 277.

Clarke, O. (2005): Atlas del Vino. Vinos y regiones vitivinícolas del mundo. Blume, Barcelona.

Cock, E. (1897): Jornada de Tarazona hecha por Felipe II en 1592, pasando por Segovia, Valladolid, Palencia, Burgos, Logroño, Pamplona y Tudela. Madrid, Imprenta y Fundición de Manuel Tello.

De La Calle Robles, L. (2002): "Denominaciones de origen y protección económica". Estudios agrosociales y pesqueros, 194.

Fernández Portela, J. (2011): "La bodega tradicional como elemento patrimonial: el cambio a la actividad industrial en la Denominación de Origen de Cigales y Ribera del Duero". Conferencia Internacional: Patrimonio Cultural de la Vid y el Vino, 8-11 febrero de 2011. Almendralejo.

Figueroa y Melgar, A. de. (1971): Viajes románticos por España. Madrid, Escuelas Profesionales Sagrado Corazón.

Franco Jubete, F. y Luis del Río, S. (2005): Cultura vitivinícola del Cerrato castellano. Viñedos, Vinos y Bodegas del Cerrato palentino. Palencia, Itagra. 
Huetz de Lemps, A. (2005): Vinos y Viñedos de Castilla y León. Valladolid, Junta de Castilla y León.

Molinero Hernando, F. et al. (2001): Inventario de productos agroalimentarios de calidad de Castilla y León. Valladolid, Junta de Castilla y León.

Molleví Bortoló, G. (2001): "Las denominaciones de origen vitivinícolas en Cataluña", en Actas del XVII Congreso de Geógrafos Españoles. Oviedo noviembre de 2001. Oviedo, Universidad de Oviedo.

Múnzer, J. (2002): Viaje por España y Portugal (1494-1495). Madrid, Ediciones Polifemo.

Piqueras Haba, J. (2005): "La filoxera en España y su difusión espacial: 1878-1926". Cuadernos de Geografía, 77.

Plasencia, P. (1995): Los vinos de España vistos por los viajeros europeos. Madrid, Ministerio de Agricultura, Pesca y Alimentación.

Ponz, A. (1962): Viage de España. Tomo XII Castille-León. Madrid, Atlas.

Provedo González, J. (1987): "La filoxera en la provincia de Logroño destrucción del viñedo y su reconstitución”. Zubia, 5.

Sánchez Hernández, J. L. (2002): "La renovación de las bases productivas en la industria vinícola de Rueda”, en R. Méndez, R. y J. L. Alonso (eds.): Sistemas locales de empresas y redes de innovación en Castilla La Mancha y Castilla y León. Salamanca, Ediciones de la Universidad de Salamanca.

Sánchez Hernández, J. L. (2003a): "Capital exógeno y procesos de innovación en la industria vinícola de la Denominación de Origen «Toro»". BAGE, 36.

Sánchez Hernández, J. L. Aparicio Amador, J. y Alonso Santos, J. L. (2003b) "Densidad institucional, gestión del conocimiento y procesos de innovación en la industria vinícola de Castilla y León". Ería, 61.

Sanz Mínguez, C.; Romero Carnicero, F; Górriz Gañán, C. y De Pablo Martínez, R. (2009): El vino y el banquete en la Ribera del Duero durante la protohistoria. Valladolid, Centro de Estudios Vacceos «Federico Wattenberg» de la Universidad de Valladolid.

Teste, L. (1959) [1872]: Viaje por España (1872). Valencia, Castalia.

Tolón Becerra, A. y Lastra Bravo, X. (2009): "Los alimentos de calidad diferenciada. Una herramienta para el desarrollo rural sostenible". Revista electrónica de Medioambiente UCM, 6.

Valdeón Baruque, J. (2006): La reconquista. El concepto de España: unidad y diversidad. Madrid, Editorial Espasa.

\section{RESUMEN}

El objetivo de esta investigación consiste en analizar las transformaciones ocurridas en la industria y en el paisaje vitivinícola de la Denominación de Origen Cigales, una de las de mayor importancia en Castilla y León.

Para poder llevar a cabo este trabajo se han utilizado diferentes fuentes estadísticas que han permitido realizar una recreación histórica de la superficie cultivada en los últimos veinte años de esta comarca, así como entrevistas a viticultores y visitas a las bodegas. 
Los resultados que se han obtenido confirman una serie de cambios de gran calado en el territorio que han contribuido a dinamizar un medio rural que languidecía económica y socialmente a través del incremento de la superficie de viñedo y la aparición de grandes bodegas industriales dando lugar a la creación de un tejido económico más diversificado con nuevas actividades ensalzando a la industria del vino como un referente clave de este territorio.

Palabras Clave: Denominación de Origen (D.O.) Cigales; Castilla y León; paisaje vitivinícola; industria vitivinícola; bodega tradicional; bodega industrial; enoturismo.

\begin{abstract}
The target of this investigation consists of analyzing the transformations that took place in the industry and in the wine scenery of the Guarantee of origin Cigales, one of those of major importance in Castile and León.

In order to carry out this task different statistical sources have been used, which have made it possible to make a historical recreation of the surface cultivated in the last twenty years in this region, as well as interviewing wine growers and visiting the wineries.

The results that have been obtained confirm a series of important changes in the territory that have contributed to energize a rural area that was languishing economically and socially through the increase of the surface of vineyard and the appearance of big industrial wineries leading to the creation of a more diversified economic textile with new activities extolling the wine industry as a key reference in this territory.
\end{abstract}

KEY WORDS: Guarantee of origin (D.O.) Cigales; Castile and León; landscape wine; wine-producing industry; traditional winery; industrial winery; enotourism.

\title{
RÉSUMÉ
}

Lobjectif de cette recherche est d'analyser les transformations dans l'industrie et du paysage du vin d'Appellation d'Origine Cigales, une des plus importants en Castilla y León. Pour mener à bien ce travail, nous avons utilisé sources statistiques différentes qui nous ont conduit à effectuer une récréation historique de la superficie cultivée au cours des vingt dernières années dans cette région, ainsi que des entrevues avec des viticulteurs et des visites des caves.

Les résultats obtenus confirment une série de changements majeurs dans le territoire qu'ils ont contribué à dynamiser une des zones rurales faible économiquement et socialement en augmentant la superficie de vignobles et de l'émergence de grands caves industrielles. De cette façon on a créé une structure économique plus diversifiée avec de nouvelles activités qui a transformé l'industrie du vin en une référence clé dans ce territoire.

Mots CLÉs: Appellation d'Origine Cigales; Castilla y León: paysage du vin; industrie du vin; cave à vin traditionnelle; cave industrielles; enotourisme. 